\title{
Diversity in older people's mental health services: black and minority ethnic groups or the universality of the rainbow?
}

\section{Introduction}

The Royal College of Psychiatrists' Old Age Faculty withdrew College Report CR156, Psychiatric Services for Black and Minority Ethnic Older People (Shah et al., 2009) in 2014. This is in line with recent United Kingdom (UK) government National Health Service proposals and the range of diversity encompassed by the Equality Act (2010). The Act refers to "protected characteristics" including age, disability, religion or belief, race (based on colour, nationality, ethnic or national origins), and sexual orientation.

An individual's personal identity is far more complex than the "black and minority ethnic" (BME) label often used in UK health and social services as a synonym for culture and diversity. The label is problematic in other ways: there is no agreed definition of BME (Office for National Statistics, 2003); broad categories ignore within-group differences; and families increasingly comprise people originating in more than one country and with more than one religion (Centre on Dynamics of Ethnicity, 2012).

CR156 was thorough. It surveyed policies and research. It reiterated earlier proposals (Ong, 2001), such as providing psychiatric assessment and treatment within mainstream services and ensuring that staff has "ethnic awareness and sensitivity." It made additional recommendations, including, to carry out research and service evaluations. CR156 gave few examples of good practice and acknowledged lack of progress in implementing existing recommendations although reasons for that were not stated.

\section{The breadth of diversity under the Equality Act, or a specific BME approach?}

People advocating specifically for BME groups are frequently concerned that some might not access services because of excessive stigma about mental illness and lack of staff understanding of their culture. However, barriers to accessing and using services are not unique to BME groups. Gay people might fear that their sexual orientation will engender rejection or criticism from psychiatric services so might avoid seeking help when it is needed. Families who accept disability in old age as normal and inevitable and expect to care for dependent older relatives frequently struggle on for long periods without seeking help.

Various other factors suggest the need to prioritize individual diversity. The 2011 Census (England and Wales) revealed that people from ethnic minorities are "spreading out," shifting the focus from geographically based groups to individuals in more mixed areas (Centre on Dynamics of Ethnicity, 2012). Living at a distance does not equate with diminished identity and the assumption that successive generations within minority groups will gradually adopt the culture of their homeland is not always borne out (Graham et al., 2014). Social class, education and intergenerational family expectations are other important influences which can affect interactions with health services.

Shifting the emphasis to individual identity and diversity has implications for staff training. Staff often know some facts about different minority groups, but that risks stereotyping patients, which can undermine individual clinical management. There may be differences within a cultural group, for example, whether to defer health decisions to family and community, which might challenge Western models of medical decision making based on personal autonomy and confidentiality (e.g. Tobert and Hinton, 2010). Exploration of personal cultural identity complements recent recommendations for mental health staff to understand their patients' spiritual needs (Cook, 2013). Understanding the individual, being able to ask the right questions, having the humility to learn from patients and their families, and reaching out to local groups should be integral to clinical work.

\section{Recent policy approaches}

Valuable initiatives such as from the Alzheimer's Society and the All-Party Parliamentary Group on Dementia have focussed on the experiences of BME communities. The Faculty collaborates 
in these initiatives (All-Party Parliamentary Group on Dementia, 2013). In addition, the Faculty's Developing an Ideal Old Age Service (Connolly and Perera, 2013) is relevant in its entirety, not just the BME section.

However, government policies seem to be moving away from referring specifically to BME groups. The National Dementia Strategy (NDS) (Department of Health, 2009) stated the need to promote access to services for everyone who needs them. The NDS took a broad approach, recognizing that people with a learning disability, those from minority ethnic groups or from rural, island or traveler communities may require specifically tailored approaches. It did not mention gay people. In the National Institute for Health and Care Excellence's (NICE) dementia guidance (2012), the breadth of person-centered care included "diversity, equality and language," also without specifically mentioning BME groups (NICE, 2012). The Prime Minister's Challenge on Dementia (Department of Health, 2012) emphasized "knowing the person, their life history and their personal culture." It did not specify groups.

The right balance needs to be achieved between group-specific guidance and strategies to provide person-centered services for people within those groups. Generic government policies which do not mention specific groups might undermine aims to achieve equality, for example, by making it harder for health service management and the unmentioned groups to engage to implement them. This has implications for clinical practice (Boardman et al., 2010). Achieving ideal services will require steadfastly sensitive and assertive local interpretation of directives concerning older people's mental health, including working directly with communities, voluntary organizations, minority-focused media, multi-disciplinary teams and health service commissioners.

\section{Conclusions}

The Faculty executive withdrew CR156, aware that this might be controversial for those who struggle to establish services for BME communities. It does not want to undermine that work, but feels that crucial and clinically relevant diversity issues affecting the complex needs of patients stretch far beyond this. Old age psychiatrists need to advocate broadly and vociferously for older people with all mental illnesses and personal identities, on national policy, local community and individual levels. Staff education to ensure person-centered clinical work is crucial, while retaining group categories for research and in localities where there are substantial populations who might require a more community focussed approach. The universality of the rainbow - including non ethnic diversity such as religious groups and gay people - needs to be our focus.

\section{Conflict of interest}

None

\section{Claire Hilton}

Visiting Researcher, Institute of Psychiatry and Consultant Old Age Psychiatrist Fairfields House, Kingsbury, NW9 0PS, London

Email: claire.hilton@nhs.net

\section{References}

All-Party Parliamentary Group on Dementia (2013). The Experiences of Black, Asian and Minority Ethnic Communities, London: Alzheimer's Society. http://www.alzheimers.org. uk/site/scripts/download_info.php?fileID $=1857$.

Boardman, J., Currie, A., Killaspy, H. and Mezey, G. (2010). Social Inclusion and Mental Health. London: Royal College of Psychiatrists.

Centre on Dynamics of Ethnicity, University of Manchester (2012). Dynamics of Diversity: Evidence from the 2011 Census. http://www.ethnicity.ac.uk/census/ 869_CCSR_Bulletin_More_segregation_or_more_mixing v7NW.pdf.

Cook, C. (2013). Recommendations for Psychiatrists on Spirituality and Religion (Position Statement PS03/2013). London: Royal College of Psychiatrists. http://www.rcpsych.ac.uk/pdf/Recommendations $\% 20$ for $\%$ 20Psychiatrists $\% 20$ on $\% 20$ Spirituality $\% 20$ and $\%$ 20Religion \%20Revised.x.pdf.

Connolly, P. and Perera, N. (2013). Developing an Ideal Old Age Service. http://www.rcpsych.ac.uk/ workinpsychiatry/faculties/oldage/aboutthefaculty/ quality.aspx\#facultyreports.

Department of Health (2009). National Dementia Strategy, London: Department of Health. https://www.gov.uk/ government/publications/living-well-with-dementiaa-national-dementia-strategy.

Department of Health (2012). Prime Minister's Challenge on Dementia. London: Department of Health. https://www.gov.uk/government/publications/ prime-ministers-challenge-on-dementia.

Graham, D., Staetsky, L. and Boyd, J. (2014). Fews in the United Kingdom in 2013: Preliminary Findings from the National Fewish Community Survey. London: Institute for Jewish Policy Research.

National Institute for Health and Care Excellence (NICE) (2012). Dementia Supporting People with Dementia and their Carers in Health and Social Care. Clinical Guideline 42, November 2006 last modified: October 2012. London: NICE. http://www.nice.org.uk/ nicemedia/live/10998/30318/30318.pdf.

Office for National Statistics (2003). Ethnic Group Statistics: A guide for the collection and classification of Ethnicity Data. 
London: ONS. http://www.ons.gov.uk/ons/guide-method/ measuring-equality/equality/ethnic-nat-identity-religion/ guide-measuring-equality/index.html.

Ong, Y. L. (2001). Psychiatric Services for Black and Minority Ethnic Older People, College Report CR103. London: Royal College of Psychiatrists.
Shah, A., Adelman, S. and Ong, Y. L., (2009). Psychiatric Services for Black and Minority Ethnic Older People, College Report CR156. London: Royal College of Psychiatrists.

Tobert, N. and Hinton, J. (2010). Somali Advocacy Research Project. http://www.mindinharrow.org.uk/ DocumentLibrary/Mind\%20in\%20Harrow.pdf. 